\title{
Strategies to deal with the COVID-19 pandemic
}

\section{Paulo NADANOVSKY(a)}

Ana Paula Pires dos SANTOS(a)

(a) Universidade do Estado do Rio de Janeiro - UERJ, Faculdade de Odontologia, Departamento de Odontologia Preventiva e Comunitária, Rio de Janeiro, RJ, Brasil.
Declaration of Interests: The authors certify that they have no commercial or associative interest that represents a conflict of interest in connection with the manuscript.

\section{Corresponding Author:}

Paulo Nadanovsky

E-mail:paulo.nadanovsky@gmail.com

ht1ps://doi.org/10.1590/1807-3107bor-2020.vol34.0068

Submitted: May 20, 2020

Accepted for publication: June 2, 2020

Last revision: June 4, 2020
Abstract: The World Health Organization declared a COVID-19 pandemic on March 11, 2020, when there were 4,293 confirmed cumulative deaths. By May 17, 2020 this number increased to 315,005. The risk of death is higher above the age of 60, but there are many deaths below 60 (for example, in Sao Paulo, 25\%). Due to the lack of a vaccine or specific treatment, there are at least three types of interventions used in the first wave of this pandemic: increased alertness and hygiene (e.g. Sweden); identification and isolation of infected people and their contacts (e.g. South Korea); lockdown (e.g. Italy). These interventions are complementary. Choices of the right mix of interventions will vary from society to society and in the same society at different times. The search for a miracle drug is dangerous because it is based on the mistaken belief that any treatment option is better than "nothing". Brazilian society will not be able to maintain lockdown for a long period. Naturally, in the near future, regardless of the advice from scientists, doctors and authorities, commerce, services and schools will reopen. In order to implement any strategy aimed to control the pandemic and preserve the economy, the country needs leadership that centralizes and coordinates actions. Unfortunately, the Brazilian government is not fulfilling this role; on the contrary, it is a hindrance. This negative leadership and lack of coordination are causing many deaths and are severely damaging the lives of survivors by delaying the resuming of economic and social activities.

Keywords: Coronavirus Infections; COVID-19; Pandemics; Public Health; Evidence-Based Practice.

\section{Introduction}

The World Health Organization (WHO) declared a COVID-19 pandemic, the disease caused by the new coronavirus SARS-CoV-2 (Severe Acute Respiratory Syndrome - Coronavirus - 2), on March 11, 2020, ${ }^{1}$ the day on which 269 new deaths were confirmed in the world (with 4,293 cumulative deaths confirmed as of that date). Brazil had the first recorded death on March 17, 2020, the day on which 596 new deaths were confirmed in the world; on May 17, 2020 Brazil and the world accumulated 16,118 and 315,005 deaths, respectively. ${ }^{2}$

The threat of COVID-19 is revealed not only by the numbers of people infected and deaths, but mainly by the number of susceptible people in 
the population who may become infected and the rate at which this occurs. SARS-CoV-2 is a new virus to which the human population has no immunity. The transmission occurs mainly through droplets and aerosols when the person talks, coughs or sneezes. The incubation period is five days (median) and ranges from two to 14 days. ${ }^{3}$ It appears that $25 \%$ of infected people are asymptomatic, i.e., they do not present symptoms during the entire period of infection, but new and better serological surveys can reveal different percentages. People presenting the symptomatic forms of the disease go through a presymptomatic phase, which appears to last for about four days, and may infect other people during this phase. ${ }^{4,5}$ It seems that the viral load is highest at the time the symptoms appear, suggesting that infectivity peaks before the symptoms appear, which can lead to much pre-symptomatic transmission. ${ }^{6}$

\section{Why is each person potentially responsible for the death of others?}

We are facing a virus with relatively high or moderate transmissibility and apparently low lethality (infection fatality ratio), although over 60 years of age the mortality among symptomatic cases is high: 60 to 69 years $4 \%$; 70 to 79 years old $8 \%$; over 80 years old $15 \%{ }^{7}$ The problem is that even a relatively low lethality, when spread over a large number of people, leads to a large number of deaths in the population. ${ }^{8}$ This is because there is no specific effective treatment to cure or prevent death by COVID-19. Another problem is that although SARS-CoV-2 often causes asymptomatic or mild illness (cough, fever, pain, and malaise), a small proportion will develop severe morbidity requiring specialized care, including respirators and intensive care unit beds. Even in the absence of effective specific treatment, care is crucial to limit suffering.

In other words, the probability of a healthy person under the age of 60 contracting the virus and requiring hospitalization is small. However, as there are millions of healthy people under the age of 60 in the population, even this small probability leads to a large number of people being admitted to hospital. In São Paulo, between March 17 and April 30, 2020, 3,877 people died with suspected or confirmed COVID-19, being
966 under 60 (25\%) and 2,911 60 or over (we used data from Sao Paulo because it is the most reliable data in Brazil; data until April 302020 because there is a delay in the register of deaths; accessed May 17 2020). In order to cause 966 deaths, the number of people in this age range who were infected must have been at least 100 times higher, i.e., 96,600, since lethality is less than $1 \%$ in this age range. As each infected person infects on average two to three people, 96,600 infected people can, in less than two weeks, infect $241,500(96,600 \times 2.5)$ new persons and so on. ${ }^{9}$

The circulation of infected people is common, as many are asymptomatic and pre-symptomatic. So, when you circulate around the city (playing football in the park or on the beach and socializing with a group of friends), you can contract the virus and, without realizing it, infect two to three people. When your infection has generated 100 infected people, the probability of a person among those 100 dying by COVID-19 is high. So, the probability of 100 infected people generating a death is high, but of one infected person (e.g. you) dying is low. That is why staying at home during an epidemic outbreak, where the number of infected people is rising and there is no vaccine or effective treatment, is an altruistic act. ${ }^{10}$

\section{How do we know whether the pandemic is increasing, stable or decreasing?}

We must understand the importance of time (or speed) to measure the severity of the COVID-19 situation. The number of deaths or of patients that need hospital intensive care may not be extraordinary if we use an annual time scale. However, on a daily, weekly and possibly monthly time scale, the severity of the COVID-19 pandemic is extraordinary.

There is an indicator of the transmissibility potential of an infectious disease called $\mathrm{R}_{0}$ ( $\mathrm{R}$ nought, or basic reproductive number), which denotes, on average, the number of people who get infected by each infected person in a population of susceptible individuals. Similarly, there is $\mathrm{R}_{\mathrm{E}}$ (effective reproductive number), which is the actual transmissibility of the disease during the epidemic when there is an increasing number of people with antibodies to the virus. $R_{0}$ can be understood as what can potentially occur and $R_{E}$ what actually (effectively) occurs. The only difference 
between $R_{0}$ and $R_{E}$ is that $R_{E}$ is not dependent on the whole population being susceptible. ${ }^{11} R_{0}$ depends not only on intrinsic aspects of the virus, but also on environmental circumstances, be they cultural (e.g. habit of hugging, kissing, physical contact in general) or housing (e.g. slums with small houses, very close to each other and with many people living together). In addition, home confinement and social isolation measures also influence $\mathrm{R}_{0} \cdot{ }^{12}$ In this case, $\mathrm{R}_{0}$ will vary depending on economic aspects (difficulty in adhering to the recommendation to stay at home, as there is a need to work daily to survive; lack of access to piped water) and on social aspects (little confidence in the authorities and their recommendations; low formal education making it difficult to obtain correct information on how to deal with this pandemic). This means that the SARS-CoV- $2 \mathrm{R}_{0}$ may be different in two countries or two cities even if the virus is genetically identical in those places.

The lower the $R_{0}$ or $R_{E}$ the better, as it means that the epidemic is spreading less. Values of $R_{E}>1$ mean that the epidemic is increasing, $R_{E}=1$ it is stabilized and $R_{E}<1$ the epidemic is decreasing.

A more reliable response about the spreading of the virus in Brazil will come when serological surveys for specific antibodies to SARS-CoV-2 are performed periodically on representative samples of the population. Fortunately, these studies are already being conducted. The first state to start was Rio Grande do Sul (RS) on April 11, 2020 and four phases with a two-week interval between them were planned. ${ }^{13}$ In the first phase, 4,189 people were tested on April 11-13 and two were positive for antibodies (IgM and IgG). Two weeks later on April 25-27, 4,500 people were tested and six were positive. On May $9-11,4,500$ were tested and 10 were positive. The authors estimated from these data that $0.05 \%$ of the population in RS had antibodies in the first phase, $0.13 \%$ in the second and $0.22 \%$ in the third. These numbers translated to 5,650 people with antibodies in RS on April 13, 15,066 on April 27 and 24,860 on May 11. The authors also estimated from the results of the third survey that, for every million inhabitants in RS, 2,200 were infected. As at that time there were only 248 reported cases, they concluded that for each case reported in the RS there were nine unreported cases $(95 \% \mathrm{CI}, 4-16)$. Finally, the authors compared the case fatality ratio in RS based on COVID-19 confirmed cases by the health authorities $(2,576)$ with this ratio based on the "real" number of cases estimated in the third RS survey $(24,860)$. As there were 105 confirmed COVID-19 deaths in RS, the case fatality ratio (lethality) applying these two alternative denominators was $4.0 \%$ and $0.42 \%$, respectively. ${ }^{14}$

This study is being conducted in the other Brazilian states (133 cities that will represent the dissemination of SARS-CoV-2 in each of the 27 states) and it was planned to consist of three surveys (phases) on May 12, May 21 and June 7, with 33,250 participants in each.

\section{Non-pharmacological measures to combat the pandemic}

Since there is no vaccine, which would reduce the number of susceptible people in the population, what would be the other way to reduce this number? By allowing the infection to follow its natural course so that after a period of time the number of people who have created antibodies reaches a sufficient proportion to achieve $R_{E}<1$. Depending on the $R_{0}$, there is a proportion of people in the population who has to develop antibodies in order to eliminate the disease $\left(\left(\mathrm{R}_{0}-1\right) / \mathrm{R}_{0}\right)$. For example, if COVID-19 $\mathrm{R}_{0}=3$ in Brazil, when $67 \%$ of the population has created antibodies to SARS-CoV-2, we can assume that the epidemic will not sustain itself and will soon be eliminated.

To get a perspective of what this means in real life, let us look at what happened in Spain during the most critical period of the first wave of the pandemic in that country. There, between March 5 and May 17, 2020 , there were 27,650 deaths recorded by COVID19 (the peak was in early April 2020 with 950 deaths recorded daily). It is estimated that, despite this large number of deaths, only $5 \%$ of the population has been infected and has produced antibodies. ${ }^{15}$ If it is necessary that $60 \%$ of the population develop immunity in order to achieve $R_{E}<1$, Spain would have to experience what it went through at that moment 12 more times. Clearly, this is unacceptable. Fortunately, it appears that lockdown as of March 14 substantially reduced the pandemic in Spain and there was already a reduction in the number of new deaths detected three weeks after the start of the 
lockdown, ${ }^{16}$ this reduction has shown itself to be large and consistent since then. ${ }^{17,18}$

There are at least three types of non-pharmacological interventions that have been used to deal with the first wave of this pandemic: a) Increased alertness and hygiene (e.g. Sweden); b) Identification and isolation of infected people and their contacts (e.g. South Korea); c) Lockdown (e.g. Italy).

\section{A) Increased alertness and hygiene (e.g. Sweden)}

Increased alertness and hygiene are changes in behaviour aimed at the entire population, so that everybody is alert to avoid agglomeration, physical contact and intensify hand washing, cleaning of personal objects and surfaces. It is necessary to involve the whole population, because asymptomatic and pre-symptomatic people can transmit the virus for several days without knowing that they are infected. This increased alertness and hygiene were also adopted in the places where interventions $b$ and $c$ above were applied; that is, interventions $b$ and $c$ include intervention a.

There are differences within each of these three types of intervention. For example, it was part of the increased alertness and hygiene in South Korea (in Asian countries generally) for everyone to wear a mask on the streets, but not in Sweden. But it seems that avoiding crowding and intensifying personal hygiene, especially hand washing, was a measure that all countries adopted.

If effective, this is possibly the best type of intervention because it keeps social and economic activities going and does not spend resources in screening programs to identify and isolate infected people. To be effective it depends on a population with a good level of formal education, cooperation, discipline and who trusts its leaders and authorities. In addition, this type of intervention depends on a competent leadership, that is, well informed, coordinated, proactive, consistent, firm, objective and clear.

It is worth warning though, that among the Scandinavian countries, Sweden has had the highest number of deaths by COVID-19 to date, May 17, 2020: Sweden 3.674; Denmark 543; Norway 232; note that it is not necessary to consider the size of the population to compare the number of COVID-19 deaths between countries. ${ }^{19}$ The overall excess mortality during the outbreaks in each of these countries was also higher in Sweden: Sweden 3,000 more deaths than usual (29\%); Denmark 200 more deaths (6\%); Norway 0 more deaths $(0 \%){ }^{20}$

\section{B) Identification and isolation of infected persons and their contacts (e.g. South Korea)}

This intervention emphasizes identifying infected people and their contacts through diagnostic tests for virus detection and their confinement for a period of two to three weeks. This intervention is expensive, difficult to implement, and requires a major effort to recruit and train workers to perform the tests and the population to adhere to the constant tests (which involves unpleasant procedures such as having a swab introduced deep in the nose or the throat). The development of complex technological and logistical resources using, for example, connected mobile phone networks and testing points across the country may be necessary in order to implement efficient contact tracing and testing in large cities. ${ }^{21}$ Testing has to be carried out frequently and on a large scale. For example, one model, possibly one of the most parsimonious, estimated that 5 million tests would be needed initially and then 20 million daily for this intervention to be successful in the USA. ${ }^{21}$ In addition, the state has to provide quarantine sites and financial aid for infected people who are unable to quarantine at home. This intervention presents ethical challenges related to the protection of privacy, nondiscrimination (that is, avoiding prejudice against infected people) and individual civil liberties. ${ }^{21}$ If well implemented, it can be reassuring (people feel reassured that there are almost no infectious people circulating between them) and effective in keeping the virus circulation restricted. As with alternative a above, this type of intervention also preserves social and economic activities in the country.

\section{C) Lockdown (e.g. Italy)}

Lockdown includes interventions such as closing trade and services, restricting transport and closing schools, up to the recommended or forced confinement of the entire population, with the exception of essential 
workers (e.g. health and food professionals, and the police). This type of intervention is the last resort in the impossibility (or failure) of the two previous interventions.

\section{Strategies to end the lockdown}

Lockdown may be effective in reducing the number of deaths and severe cases of COVID-19, but it is not a realistic option to confine people for many months. If economic activity becomes depressed, at the level it remains during lockdown, for more than a few months, the number of deaths caused by the economic downturn may be greater than that avoided by COVID-19.22 There is really no choice between protecting health or protecting the economy; protecting the economy is a fundamental part of health protection. Therefore, we must urgently create strategies to end the lockdown. It is important to recognize that there are positive health effects of the lockdown, which offset, at least in part, its negative effects, such as a reduction in deaths and hospitalizations due to: traffic crashes; violence; air pollution; viruses in general; gastrointestinal diseases; unnecessary elective procedures due to overdiagnosis and overtreatment. In addition, the closing of schools and emphasized hygiene habits, such as hand washing, should reduce the circulation of viruses and microorganisms in general, reducing the diseases that originate in schools and hospitals, consequently reducing the contagion of parents, grandparents and family members in general, by children and health professionals.

Brazil began the lockdown earlier in the course of its outbreak (at least Sao Paulo and Rio de Janeiro) than other countries such as Italy, Spain, the United Kingdom and the USA. ${ }^{16}$ Therefore, it seemed that there would be fewer deaths and severe cases in Brazil than in these countries during the first wave of this pandemic. It seemed plausible that the exit from the lockdown in Brazil could occur after a smaller trauma than in these other countries. But, unfortunately, it seems that Brazil missed the opportunity to learn from the countries that preceded it during the first wave of this pandemic, giving signs that the number of deaths here will be even higher than in the countries that suffered the most. ${ }^{17}$
In any case, the exit from the lockdown will occur at some point and it is expected that it will be carried out cautiously. Caution means starting the exit only when there is an indication of $R_{E}<1$ (on May 8, 2020, none the five most affected Brazilian states seemed to have been able to reach $R_{E}<1$ ). ${ }^{23}$ When this time comes, it will be necessary to emphasize the investment in increased alertness and hygiene like Sweden, and in the identification and isolation of infected people and their contacts like South Korea.

The identification and isolation of infected people and their contacts may be unrealistic for Brazil. If it has not been possible to apply this intervention so far, it seems unlikely that it will be applied at the time of relaxing the lockdown. This is an intervention that demands an investment that is possibly beyond Brazil's capacity at this historical, social and economic moment. If there is sufficient political will and effort from society to apply this intervention though, it will reduce the risk that in the coming months or years we will have to resort to lockdown periodically, which causes so much social, psychological and economic harm. ${ }^{19}$

A precarious alternative, in the absence of diagnostic tests, would be to focus the identification of infected persons among those who seek hospital care, have COVID-19 confirmed and their contacts. This is precarious because it does not identify many people with asymptomatic, mild and pre-symptomatic disease (but it is better than no surveillance at all). This alternative must be supported by the government through providing sites for quarantine and financial help for people who are unable to stay at home and stop working during quarantine.

Epidemiologic surveys with rapid serologic antibody tests ${ }^{11}$ are likely to be the key tool to help us deal with this pandemic, which could last until 2022 (and even resurface in 2025)..$^{12}$ These tests are likely to act as the speedometer that will indicate the rate of virus transmission; this will help us accelerate or step on the brake by opening or closing schools and trade, exiting or starting lockdown, etc.

Another role to be considered for serological tests is the "immunity passport" or "immunity-based license". In this case, the objective is to identify people in the population who are able to leave home confinement 
and speed up the resumption of economic and social activities. The accuracy of the serological test for antibodies to SARS-CoV-2 currently in use in Brazil is relatively good, but for the immunity-based license, the usefulness of the test depends on the prevalence of people with antibodies in the population. Even with a very good specificity (99\%) a positive result is more likely to be false than true when the prevalence is $1 \%$. This means that for a person with a positive result, the probability of not having antibodies is greater than that of having antibodies. In possession of such an "immunity-based license", the person and others should not feel reassured, as they are more likely to be susceptible than immunized. ${ }^{24}$ On the other hand, in a population with $10 \%$ or $20 \%$ of people with antibodies, a positive result in this test shows a high probability that the person does have antibodies and is no longer at risk of becoming infected or infective.

These accuracy estimates are based on the aggregate population and ignore the clinical history that would modify pre-test probabilities. Within the general population and special populations, such as health professionals, there are individuals with and without a history of what sounds like COVID19, including those with no history, atypical, mild, moderate and severe. In each of these histories there is a different pre-test probability, which can vary from 2 to $80 \%$, for example. In short, the usefulness of this type of test to assist in the release of certain individuals, that is, in providing immunity-based licenses, depends on a prevalence of at least $10 \%$ (or perhaps $20 \%$ ) of people with antibodies in the reference population..$^{24}$

It has not yet been proven whether antibodies to SARS-CoV-2 confer immunity and if so, for how long. Therefore, this type of test may be irrelevant if the antibodies do not confer immunity or confer it for a short period of time. For the time being, based on studies with monkeys and evidence of other viruses in humans, it is assumed that immunity has been acquired for at least two years. ${ }^{12}$

In the near future, the science behind this type of test is expected to be more conclusive. Assuming that antibodies are indeed neutralizing the virus for a long time; that the prevalence of people with antibodies in populations is greater than 10 or $20 \%$, or that more accurate new tests are created, and reach $100 \%$ or almost $100 \%$ specificity, that is, rarity or absence of false-positive results; these tests can be a valuable aid to the prudent opening of society during epidemic waves in which society has been placed under strict norms of limiting mobility and outside activities.

There are ethical and practical challenges that will need to be addressed by societies that choose to issue the immunity-based license (or immunity passport), including the following: ${ }^{25}$ stigma (discrimination) and social prejudice of people without the license; increased inequality in favour of those who can afford to pay for the license; market for issuing the licence susceptible to fraud; errors in the test that would lead to issuing the licence to people who should not obtain it. Experts in bioethics made an excellent analogy with the license to drive. From this analogy they were able to answer convincingly all questions and concluded that, although immunity-based licensing requires care for implementation and solid scientific support, none of the objections identified so far make them unethical in principle. ${ }^{25}$

A strategy that would probably be prudent, fair and efficient to speed up exiting lockdown is as follows: when the proportion of people with antibodies in the general population is small $(<10 \%)$, emphasize the identification and isolation of the infected (frequent tests to detect the presence of the virus). ${ }^{21}$ When this proportion exceeds $10 \%$, also emphasize the issuance of immunity-based license through tests to detect the presence of antibodies. ${ }^{25}$

If there is not enough political determination and coordination (competence) or economic, social, technological or cultural conditions to promote lockdown relaxation through virus and antibody detection tests, the alternative will be "trial and error" type of relaxation. In this case, the end of home confinement, the opening of schools, commerce and services and the release of transportation may consist of the release of the entire population at once at a given time. Alternatively, opening can begin gradually, for example, in weekly waves, directing the lockdown relaxation to distinct occupational groups. For example, it may initially release workers from sectors that depend most on being away from 
home to carry out their activities (factory workers, construction workers, shopkeepers, etc.) and later those who are able to carry out a large part of their tasks at home (teachers, researchers, journalists, etc.). The criteria will obviously vary according to the specificities of each city, state and country.

The "trial and error" type of lockdown relaxation is risky because a large number of susceptible, asymptomatic, pre-symptomatic and infective individuals are released at the same time, creating a social environment conducive to virus transmission, which can lead to uncontrolled epidemic and in a short time the need for new closures and even lockdown. The advantages are the rapid and vigorous resumption of economic and social activity and the faster increase in the number of infected individuals who will produce antibodies, contributing to the reduction in the value of $R_{E}$ (all other factors remaining constant). If this type of lockdown relaxation is adopted at a time when there is still much transmission of the infection, it can cause an increase in the number of severe cases above what the health services would be able to take; for example, as of May 8, 2020, it was estimated that the five most affected Brazilian states had $R_{E}>1$, so, the epidemic was still growing. ${ }^{23}$ If the number of new cases does not cause disruption to the health service and a relatively small number of deaths occur, this alternative would be a success. However, it is hard to believe that this success will be achieved when $R_{E}>1$.

In the end, the moment of exiting lockdown will not really be a "moment"; historically, considering past pandemics, the end of a pandemic is diffuse and determined not only (and perhaps not mainly) by medical and health considerations, but more by the social pressure of people wanting to return to normal life. The population is becoming inpatient and gradually returning to normal life, even with the health risks and the high number of deaths. ${ }^{26} \mathrm{It}$ remains for health authorities and governments to try to reduce the transmission of infection as much as possible, while there is social collaboration.

It is plausible that the world will have to deal with the comings and goings of this COVID-19 pandemic in the next two to four years. ${ }^{12}$ There may be critical times when other periods of lockdown will be necessary if effective treatment or vaccine is not available. Therefore, it is important that we come up with creative ideas for exiting lockdown, not only in this first wave we are going through, but also for other similar situations in the future. Some creative ideas are already emerging and certainly many will be tested, improved and adapted. For example, starting with a system based on a twoweek time schedule (considering the incubation period of the virus), 10-4, that is, 10 days at home and 4 out. $^{27}$

The three interventions discussed in this article are alternatives that do not exclude each other. On the contrary, they are complementary. The choices of the right mix will vary from society to society and in the same society at different times. Each of these strategies has advantages and disadvantages that vary primarily according to the prevalence of susceptible people in the population and the rate of infection transmission. Other important variables that should be considered are: available resources (diagnostic tests, places for physical isolation, health facilities to care for severe cases); socioeconomic conditions (financial reserves to sustain drastic reduction in economic activity, housing and sanitation conditions, population density); culture (discipline, confidence in the authorities, valuing of science, respect for laws and social norms, hygiene habits).

\section{Scientific evidence during the pandemic}

It is understandable that in the face of a pandemic like COVID-19, the population, the media and health professionals are anxious to obtain information about diagnostic tests, treatment alternatives and the prognosis of the disease. As it is an unknown disease, it is natural that researchers initially publish case series studies. The problem is that, in the eagerness to obtain quick answers, these case series have been used to gather information about the effectiveness of different treatments. However, this study design is a precarious and rudimentary way of evaluating the effectiveness of treatments, with serious consequences, including the large-scale adoption of treatments that can increase morbidity and risk of death. 
COVID-19 may be an unknown disease, but its consequences are known to doctors. For example, fever, pain, shortness of breath, and the other symptoms related to COVID-19 are familiar situations that doctors are used to dealing with. The clinical management of various diseases, not only COVID-19, consists of offering palliative and supportive care. Often it is the patient's own defensive mechanisms that react effectively, independently of the medical treatment received. With COVID-19 it is no different. The vast majority of patients react and recover from the disease. $^{28}$

In addition, there are medical and pharmacological resources to help patients cope with COVID-19, such as analgesics, antipyretics, oxygen masks, mechanical respirators; these resources can be lifesaving. There is then a standard care to help patients with COVID-19. Therefore, the question we have to answer is the following: do patients who receive a certain drug (any new drug or an existing drug, but not yet used in patients with COVID-19), in addition to the standard care, show improved prognosis of COVID-19 (that is, reduced risk of dying, sequelae or length of hospital stay) in comparison to patients who receive standard care only? Let us see how case series cannot answer this question. For example, it may be that the risk of dying in hospitalized patients infected with SARS-CoV-2 who receive standard care is $8 \%$. A drug, in addition to standard care, would have to reduce this risk from $8 \%$ to, for example, $4 \%$ to be considered effective. Imagine a doctor who treated 100 patients with standard care associated with this drug. He noticed that only 8 patients died. He then publishes an article reporting that he treated 100 patients with the drug and only 8 died, concluding that the drug is a success. As there were no patients receiving only the standard care, he could not realize that even without the drug the number of patients dying would also be 8 . The lack of a comparison group makes the case series a precarious modality of study design to discover effective treatments for COVID-19.

As there is no known effective treatment specific to COVID-19, a source of information may be the experience and feeling of the physicians when evaluating each patient individually ("gut feeling"). This lack of evidence allows the ethical use of experimental treatments, still without scientific proof of effectiveness, the so-called compassionate use. ${ }^{29}$ This experimental situation should be made explicit and shared by the doctor with the patient and the patient's family in order to decide whether the doctor will only provide the standard care or associate it with an experimental drug. The problem is that there are physicians who cannot conceive that something they believe in so much has to be considered an experimental treatment.

The search for effective treatments or preventive measures should rely on the randomized controlled trial (RCT). This is the study design that provides the most robust and reliable evidence. At this moment of so much doubt and fear, the RCT should be emphasized even more. It is worth noting that one of the frustrations usually associated with the RCT is the long time it takes to be performed, especially when researchers have to follow participants for long periods of time until the outcomes of interest occur. In the case of COVID-19, because it is a fast course disease, the outcomes of interest (e.g., death, length of stay and lung damage) occur within one or two months; this allows the RCT to be completed in a relatively short time.

Better than one RCT are all the RCTs already performed on a given subject, so a systematic review of RCT provides the best answer about treatment effectiveness. However, a systematic review takes time to complete, so we have seen an increasing number of rapid reviews. It should be noted that the certainty of evidence obtained from a rapid systematic review is the same as in a traditional systematic review, provided that all steps are maintained and there is no loss of quality during the process. This is possible using software that makes the review process more automated and when experienced researchers dedicate their time exclusively to this work. ${ }^{30}$

Preprints is another method for sharing scientific evidence during the COVID-19 pandemic. These are scientific articles made freely available in repositories (e.g., bioRxiv and medRxiv) without prior peer review. Preprints in the health area have recently gained more attention because the storage capacity of the repositories is much greater than that of conventional 
journals, ${ }^{31}$ and they allow authors to quickly make available study results that can have an immediate impact on the management of the disease. Many health policies during the pandemic are being guided by preprints. ${ }^{32}$ The negative side of the preprint is the absence of peer review, which often leads to the publication of studies with gross methodological errors that threaten confidence in the results. The positive side is the rapid dissemination of results and visibility, allowing the scientific community to have quick access to the study and make their critiques and contributions openly.

An extraordinary amount of research has been carried out recently on several topics related to COVID-19. While this shows the admirable effort and vigour of the scientific community to react quickly to seek solutions, it also reveals a lack of coordination to minimize duplication of efforts and maximize available resources. For example, there are more than 1,500 records of ongoing studies related to COVID-19 on the ClinicalTrials.gov platform..$^{33}$ Of these, more than 900 are RCTs, of which more than 400 are currently recruiting participants. Many studies with the same hypotheses lead to a competition for participants, besides being a missed opportunity to test different hypotheses. ${ }^{34}$ There are several small and isolated RCTs testing the same drugs, some of which will probably not manage to recruit enough patients to be able to detect differences between the groups being compared..$^{35}$ It would be better to perform multicentric, adaptive RCTs, which test a range of potential treatments simultaneously and are able to recruit patients with different profiles and varied clinical conditions more quickly. An example of this type of RCT is the Recovery Trial. ${ }^{36}$ In addition, it is important that there is a monitoring system to avoid publication bias. There are attempts to create a register that captures all RCTs related to COVID-19. ${ }^{37}$ There has also been much duplication of effort in conducting systematic reviews on COVID-19. For example, as of May 18, 2020, there were 925 records of systematic reviews related to COVID-19 in PROSPERO; at least 50 aim to evaluate the effectiveness and/or safety of chloroquine/hydroxychloroquine (alone or combined with another drug) in treating COVID-19. ${ }^{38}$

\section{Drugs}

The frantic search for a miracle drug is dangerous because it is based on and leads to the mistaken belief that any treatment option is better than nothing, after all, what harm can a drug do when there is no other treatment option available? However, it is not true that there is "nothing". As argued already, there is the standard care and the natural defence mechanisms of the individual against the disease. In addition, medications have adverse effects, often severe, and only by carrying out an RCT is it possible to know whether a medicine does more good than harm. That is, when a drug with an unknown clinical effect (or known, but in patients with other diseases) is administered to patients with severe diseases, such as COVID-19, there is no way to know whether the patients have benefited or harmed themselves unless they have been compared to a control group. ${ }^{39}$

The case of chloroquine and hydroxychlorine is emblematic. One of the main appeals of these drugs is that they have been used for many years to treat patients with malaria, lupus, rheumatoid arthritis and other autoimmune diseases. This would already ensure their safety. However, this is indirect evidence: they may be safe for those, but harmful for COVID19 patients. Nevertheless, in the last few months they have gained prominence, as some physicians and researchers have begun to consider them as an option for the treatment of COVID-19. In March 2020, the WHO approved studies with these drugs for the treatment of patients with COVID-19. World leaders were enthusiastic about these drugs and advocated that they would be the cure for COVID-19; this caused a frantic search for these drugs in pharmacies, leaving patients with other diseases without access to them. Promising in vitro studies and preliminary results of clinical studies with poor methods led to a distorted view of reality, causing many physicians, the media and the population to believe in this "miracle drug". There are several reports on social networks of people claiming that they have been saved by chloroquine or hydroxychloroquine. Obviously, no individual can know whether or not he was saved by some treatment, because it is not possible to know whether he would have survived or recovered in the absence of the treatment. 
This unscientific atmosphere, fostered by some political leaders, physicians and researchers, makes the execution of RCTs difficult. People hear in the media that chloroquine and hydroxychloroquine are effective and safe. Thus, patients and family members may not agree to participate in studies where they will be randomly allocated either to chloroquine/ hydroxychloroquine, or another drug or a placebo. ${ }^{40}$ Who will agree to receive another drug or a placebo when an "effective and safe" drug is available?

Unfortunately, many of the studies conducted on COVID-19 used poor methods, including those that aimed to evaluate the effectiveness of chloroquine and hodroxicloquine; a regrettable waste of time and resources. ${ }^{41}$ Several clinical studies were conducted without a control group. There was also a comparison with a historical control group, not internal to the study, which eliminated the crucial role of randomization. ${ }^{42}$ In many studies there was also no blinding of the assessment of the outcome, and often the outcomes used were subjective, such as improvement of symptoms or radiological imaging ${ }^{35}$.

A rapid systematic review on the effectiveness and safety of hydroxychloroquine and chloroquine for COVID-19 $9^{43}$ included, so far, 120 comparative clinical studies, but 109 are still ongoing, so the results refer to 11 studies with available data: three randomized open clinical trials (China), one non-randomized clinical trial (France), one prospective cohort (China) and six retrospective cohort (USA, United Arab Emirates, China and multinational). All studies presented limited methodological quality and were heterogeneous regarding several aspects, such as study design (randomized and non-randomized), outcomes (negative viral load, radiological progression, time for clinical improvement, need for mechanical ventilation, intensive care unit lengths of stay, adverse effects, mortality), severity of disease (mild or critical); dose of hydroxychloroquine (200, 400 and $600 \mathrm{mg}$ /day); method of data analysis (intention to treat and per protocol); type of publication (peer-reviewed or not). The results of these studies are somewhat controversial and the risk of bias is high, which compromises the confidence in the results. Therefore, the efficacy and safety of hydroxychloroquine and chloroquine in patients with COVID-19 are still uncertain and we should wait for the results of ongoing randomized clinical trials for a better understanding of the effects of this drug in patients with COVID-19.

Given the emergency situation and the search for effective treatments, other drugs used for other diseases have been studied and identified as possible treatment alternatives for COVID-19, among them remdesivir, ivermectin and heparins. However, so far, there is not enough evidence to establish the real harms and benefits of these drugs for the treatment of COVID-19. ${ }^{44,45,46}$ There are many studies in progress and, as new evidence becomes available, recommendations on the use of these drugs for the treatment of COVID-19 may change.

At this time of crisis, world leaders, public health authorities, physicians, regulatory agencies and all kinds of media must be careful to seek and disseminate reliable information in order not to support the use of therapies of unproven effectiveness. Their claims influence the belief and behaviour of the population, leading, for example, to an increase in internet searches for purchasing these unproven drugs. ${ }^{47}$

In the absence of evidence of effectiveness and safety of a drug, standard treatment may be the best option. We must be careful not to fall into the temptation to give in to obscurantism and weaken science. However, as we have already pointed out, there are two perspectives that we must accommodate: the individual case of each doctor-patient dyad and public policy. On the one hand, doctors may face difficult clinical situations where the patient is getting sicker and she feels that she should try a specific medication beyond the standard care. In such cases, with the consent of the family and awareness of the uncertainties regarding effectiveness and safety, the doctor could prescribe these medications as a last resort. On the other hand, it is irresponsible to adopt a public policy for the prescription of any drug without proven benefits and safety from RCTs.

\section{Vaccines}

In addition to the extensive search for treatment for COVID-19, many researchers are seeking an effective vaccine. There are more than 100 vaccines being developed ${ }^{48}$ International scientific leaders and experts in infectious disease epidemiology believe 
that the only way to get back to normal life will be when an effective vaccine is available for the entire world population. ${ }^{12}$

The production of a vaccine is a time-consuming process and obtaining a vaccine within a period of one to two years would be unprecedented. The safety of the vaccine is a crucial aspect to be investigated as it could make subsequent infection with SARS$\mathrm{CoV}-2$ more severe. ${ }^{49}$

The "Human Challenge Studies" may accelerate this process, as they require fewer participants and shorter follow-up time than the usual effectiveness and safety studies. In these studies, participants get infected on purpose in a controlled experimental setting, rather than waiting for the infection to occur naturally. Volunteers are young, healthy and living in areas where the virus is circulating. They would be monitored and receive treatment if they became ill. The two main limitations of this proposal are a) obtaining evidence of effectiveness in a specific group (young and healthy) other than the group most in need of the vaccine (elderly and chronically ill); and $b$ ) the risk of death of a healthy volunteer, even if small, since there is no effective treatment for the disease. Still, there are compelling arguments that make this proposal feasible and promising..$^{50}$

\section{Masks}

The wearing of masks by the entire population is controversial. Its use is defended by the precautionary principle, which says that "in cases of serious or irreversible threats to health or ecosystems, recognizing that there is scientific uncertainty should not be used as a reason to postpone preventive measures." ${ }^{11}$ If on the one hand there is a lack of robust evidence from RCT, on the other hand we are facing a highly transmissible disease, against which we have no immunity and which is causing deaths and collapse in health systems. The logic would be that the mask would protect the other, because the user would not expel contaminated droplets if she were an asymptomatic (or symptomatic) carrier. However, it can be argued that it would also protect the user, as it would be a barrier preventing contaminated droplets from the other reaching the user's mouth and nose. Due to the lack of evidence, researchers questioned the benefit and warned about the possible adverse effects related to the wearing of masks by the general public, such as its misuse and the false sense of security. Mask wearing could lead to relaxation (or devaluation) of other preventive methods, such as social distancing and hand washing. ${ }^{52}$ Those who argue in favour remind that no RCT has been performed to assess the effects of lockdown or hand washing either.

Possibly, the best justification in favour of wearing a mask, even in the absence of evidence from RCT, would be the low potential for harm, as opposed to taking drugs without evidence from RCT, which has high potential for harm. However, it is intriguing and frustrating to notice the enormous amount of registered RCTs for testing drugs compared to the minimum amount for evaluating the effect of masks, a simple and inexpensive intervention. .33,54 $^{2}$

\section{Conclusions}

In order to implement any strategy aimed to control the pandemic and preserve the economy, the country needs leadership that centralizes and coordinates actions. Unfortunately, the Brazilian government is not fulfilling this role; on the contrary, it is a hindrance. This negative leadership and lack of coordination are causing many deaths and are severely damaging the lives of survivors by delaying the resuming of economic and social activities.

At this moment it is not possible to predict when the first wave of this pandemic will be under control in Brazil, what (and how) economic and social activities will be compatible with pandemic control, and when (and if) there will be specific effective vaccine or treatment.

Brazilian society will not be able to maintain the lockdown for a long period. Naturally, in the near future, regardless of the advice from scientists, doctors and authorities, commerce, services and schools will reopen. A lack of a responsible and proactive central leadership in consonance with the best scientific evidence, increases the risk of a tragedy in the near future. Unless we take urgent action, there may be an economic debacle, social unrest and a slaughter never witnessed by current generations. 


\section{References}

1. World Health Organization. WHO Director-General's opening remarks at the media briefing on COVID-19 - 11 March 2020.2020 Mar 11. Available from: https://www.who.int/dg/speeches/detail/who-director-general-s-opening-remarks-at-the-media-briefing-on-covid-19--11-march-2020

2. Roser M, Ritchie H, Ortiz-Ospina E, Hasell J. Coronavirus pandemic (COVID-19). 2020. Available from: https://ourworldindata.org/ coronavirus

3. Desai AN, Patel P. Stopping the spread of COVID-19. JAMA. 2020;323(15):1516. https://doi.org/10.1001/jama.2020.4269

4. Kimball A, Hatfield KM, Arons M, James A, Taylor J, Spicer K, et al. Asymptomatic and presymptomatic SARS-CoV-2 infections in residents of a long-term care skilled nursing facility - King County, Washington, March 2020. MMWR Morb Mortal Wkly Rep. 2020 Apr;69(13):377-81.

5. Wei WE, Li Z, Chiew CJ, Yong SE, Toh MP, Lee VJ. Presymptomatic transmission of SARS-CoV-2 - Singapore, January 23-March 16, 2020. MMWR Morb Mortal Wkly Rep. 2020 Apr;69(14):411-5.

6. Wolfel R, Corman VM, Guggemos W, Seilmaier M, Zange S, Muller MA, et al. Virological assessment of hospitalized patients with COVID-2019. Nature. 2020;581:465-9. https://doi.org/10.1038/s41586-020-2196-x

7. Worldometer. Age, sex, existing conditions of COVID-19 cases and deaths. 2020 May 13. Available from: https://www.worldometers. info/coronavirus/coronavirus-age-sex-demographics/

8. Rose G. Sick individuals and sick populations. Int J Epidemiol. 1985;14(1):32-8. https://doi.org/10.1093/ije/14.1.32

9. Portal da Transparência. Especial COVID-19. Available from: https://transparencia.registrocivil.org.br/especial-covid

10. Nadanovsky P. The tragedy of the commons and the coronavirus pandemic. 2020 Mar 21. Available from: https://nadanovsky.blogspot. com/2020/03/the-tragedy-of-commons-and-coronavirus.html

11. Halloran ME. Concepts of infectious disease epidemiology. In: Rothman KJ, Greenland S, editors. Modern epidemiology. 2nd ed. Philadelphia: Lippincott-Raven Publishers; 1998. p. 529-54.

12. Kissler SM, Tedijanto C, Goldstein E, Grad YH, Lipsitch M. Projecting the transmission dynamics of SARS-CoV-2 through the postpandemic period. Science. 2020 May;368(6493):860-8. https://doi.org/10.1126/science.abb5793.

13. Hallal PC, Horta BL, Barros AJD, Dellagostin OA, Hartwig FP, Pellanda LC, et al. Evolução da prevalência de infecção por COVID-19 no Rio Grande do Sul: inquéritos sorológicos seriados. Cien Saude Colet. 2020. https://doi.org/10.1590/SciELOPreprints. 41

14. Estado do Rio Grande do Sul. Secretaria de Planejamento, Orçamento e Gestão. Epicovid19. Epidemiologia da COVID-19 no Rio Grande do Sul: estudo de base populacional. 2020 May 13. Available from: https://estado.rs.gov.br/upload/arquivos//fase3-epicovid13mai20.pdf

15. Ministerio de Ciencia e Inovación, Ministerio de Sanidad (ESPAÑA). Estudio ENE-COVID19: primera ronda. Estudio nacional de seroepidemiología de la infección por SARS-COV-2 en ESPAÑA: Informe preliminar 13 de mayo de 2020. Available from: https://www. ciencia.gob.es/stfls/MICINN/Ministerio/FICHEROS/ENECOVID_Informe_preliminar_cierre_primera_ronda_13Mayo2020.pdf

16. Nadanovsky P. Número diário registrado de novas mortes pela COVID-19 nas três primeiras semanas após a primeira morte registrada pela COVID-19. 2020 Apr 8. Available from: https://nadanovsky.blogspot.com/2020/04/numero-diario-registrado-de-novas_8.html

17. Nadanovsky P. Brasil continua aumentando o número de mortes diárias registradas por COVID-19. 2020 May 8. Available from: https:// nadanovsky.blogspot.com/2020/05/brasil-continua-aumentando-o-numero-de.html

18. Nadanovsky P. Por que o Brasil, mesmo depois de mais de quatro semanas de confinamento domiciliar, ainda apresenta aumento no número de mortes diárias registradas? 2020 Apr28. Available from: https://nadanovsky.blogspot.com/2020/04/

19. Nadanovsky P. Está errado comparar o número de mortes pela COVID-19 entre países sem considerar o tamanho da população em cada país? Não. 2020 May 18. Available from: https://nadanovsky.blogspot.com/2020/05/esta-errado-comparar-o-numero-de-mortes_18.html

20. Financial Times. Coronavirus business update. Available from: https://www.ft.com/content/a26fbf7e-48f8-11 lea-aeb3-955839e06441

21. Harvard University. Edmond J. Safra Center for Ethis. Roadmap to pandemic resilience. 2020 Apr 20. Available from: https://ethics. harvard.edu/covid-roadmap

22. Thomas P. J-value assessment of how best to combat Covid-19. Nanotechnology Perceptions. 2020;16:16-40. https://doi.org/10.4024/N02TH20A.ntp.16.01

23. Mellan TA, Hoeltgebaum HH, Mishra S, Whittaker C, Schnekenberg RP, Gandy A, et al. Report 21: Estimating COVID-19 cases and reproduction number in Brazil. Imperial College London. 2020 May 8. https://doi.org/10.25561/78872

24. Nadanovsky P. The usefulness of the SARS-CoV-2 antibody test. 2020 Apr 26. Available from: https://nadanovsky.blogspot. com/2020/04/the-usefulness-of-sars-cov-2-antibody.html

25. Persad G, Emanuel EJ. The Ethics of COVID-19 immunity-based licenses ("immunity passports"). JAMA. 2020 May 6. https://doi.org/10.1001/jama.2020.8102

26. Kolata G. How pandemics end. The New York Times. 2020 May 10. Available from: https://www.nytimes.com/2020/05/10/health/ coronavirus-plague-pandemic-history.html 
27. Alon U, Milo R, Yashiv E. 10-4: How to reopen the economy by exploiting the Coronavirus's weak spot. 2020 May 11. Available from: https://www.nytimes.com/2020/05/11/opinion/coronavirus-reopen.html

28. Wu Z, McGoogan JM. Characteristics of and Important lessons from the Coronavirus disease 2019 (COVID-19) outbreak in China: summary of a report of 72314 cases from the Chinese center for disease control and prevention. JAMA. 2020;323(13):1239-1242. https://doi.org/10.1001/jama.2020.2648

29. Borysowski J, Gorski A. Compassionate use of unauthorized drugs: legal regulations and ethical challenges. Eur J Intern Med. 2019 Jul;65:12-6. https://doi.org/10.1016/i.ejim.2019.04.008

30. Clark J, Glasziou P, Del Mar C, Bannach-Brown A, Stehlik P, Scott AM. A full systematic review was completed in 2 weeks using automation tools: a case study. J Clin Epidemiol. 2020 May;121:81-90. https://doi.org/10.1016/i.jclinepi.2020.01.008

31. Kupferschmidt K. Preprints bring 'firehose' of outbreak data. Science. 2020;367(6481):963-4.

32. Majumder MS, Mandl KD. Early in the epidemic: impact of preprints on global discourse about COVID-19 transmissibility. Lancet Glob Health. 2020;8(5):e627-e30. https://doi.org/10.1016/S2214-109X(20)30113-3

33. U. S. National Library of Medicine. ClinicalTrials.gov. Available from: https://clinicaltrials.gov/

34. London AJ, Kimmelman J. Against pandemic research exceptionalism. Science. 2020;368(6490):476-7. https://doi.org/10.1126/science.abcl731

35. Bauchner H, Fontanarosa PB. Randomized clinical trials and COVID-19: managing expectations. JAMA. 2020 May 4. https://doi.org/10.1001/jama.2020.8115

36. RECOVERY. Randomized evaluation of Covid-19 therapy. Available from: https://www.recoverytrial.net/

37. Thorlund K, Dorn L, Park H, Hsu G, Forrest JI, Mills EJ. A real-time dashboard of clinical trials for COVID-19. Lancet Digital Health 2020 Apr 24. Available from: https://doi.org/10.1016/\$2589-7500(20)30086-8

38. National Institute for Health Research. PROSPERO: International prospective register of systematic reviews. Available from: https://www. crd.york.ac.uk/prospero/

39. Kalil AC. Treating COVID-19 - Off-Label Drug Use, Compassionate Use, and Randomized Clinical Trials During Pandemics. JAMA. 2020 May;323(19):1897-1898. https://doi.org/10.1001/jama.2020.4742

40. Ledford H. Chloroquine hype is derailing the search for coronavirus treatments. Nature. 2020 APR;580(7805):573. https://doi.org/10.1038/d41586-020-01165-3

41. Alexander PE, Debono VB, Mammen MJ, lorio A, Aryal K, Deng D, et al. COVID-19 research has overall low methodological quality thus far: case in point for chloroquine/hydroxychloroquine. J Clin Epidemiol. 2020. https://doi.org/10.1016/i.jclinepi.2020.04.016

42. Borba MGS, Val FFA, Sampaio VS, Alexandre MAA, Melo GC, Brito M, et al. Effect of high vs low doses of chloroquine diphosphate as adjunctive therapy for patients hospitalized with severe acute respiratory syndrome Coronavirus 2 (SARS-CoV-2) infection: a randomized clinical trial. JAMA Netw Open. 2020;3(4):e208857. https://doi.org/10.1001/jamanetworkopen.2020.8857

43. Pacheco RL, Pachito DV, Bagattini AM, Oliveira Junior HÁ, Riera R. Hidroxicloroquina e cloroquina para COVID-19: revisão sistemática - atualização 25/05/2020. Available from: https://oxfordbrazilebm.com/wp-content/uploads/2020/05/RS_rapida_hidroxicloroquina_ COVID19_atualizacao_25_05_20.pdf

44. Pan American Health Organization. World Health Organization. Ongoing living update of potential COVID-19 therapeutics: summary of rapid systematic reviews. 2020 Apr 22. Available from: https://iris.paho.org/handle/10665.2/52025

45. Riera R, Bagattini AM, Pachito DV, Medeiros FC, Brito GV, Matuoka JY, et al. Heparinas para infecção por SARS-CoV-2 (COVID-19): revisão sistemática rápida. 2020 May 1. Available from: https://oxfordbrazilebm.com/wp-content/uploads/2020/04/RS_rapida_ HEPARINAS_COVID19_01_05_20.pdf

46. Riera R, Pacheco RL, Latorraca COC, Fontes LE, Martimbianco ALC. Remdesivir para infecção por SARS-CoV-2 (COVID-19). Revisão sistemática. Available from: https://oxfordbrazilebm.com/wp-content/uploads/2020/05/RS_rapida_REMDESIVIR_COVID19_29_05_20.pdf

47. Liu M, Caputi TL, Dredze M, Kesselheim AS, Ayers JW. Internet searches for unproven COVID-19 therapies in the United States. JAMA Intern Med. 2020 Apr 29. 2020. https://doi.org/10.1001/jamainternmed.2020.1764

48. Milken Institute. COVID-19 Treatment and vaccine tracker. Available from: https://milkeninstitute.org/covid-19-tracker

49. Graham BS. Rapid COVID-19 vaccine development. Science. 2020. May;368(6494):945-6. https://doi.org/10.1126/science.abb8923.

50. Eyal N, Lipsitch M, Smith PG. Human challenge studies to accelerate Coronavirus vaccine licensure. J Infect Dis. 2020;221(11):1752-6. https://doi.org/10.1093/infdis/jiaa152

51. Martuzzi M, Tickner JA, editors. The precautionary principle: protecting public health, the environment and the future of our children. Geneva: World Health Organization; 2004.

52. Cheng KK, Lam TH, Leung CC. Wearing face masks in the community during the COVID-19 pandemic: altruism and solidarity. Lancet. 2020 Apr 16. https://doi.org/10.1016/S0140-6736(20)30918-1

53. Greenhalgh T, Schmid MB, Czypionka T, Bassler D, Gruer L. Face masks for the public during the Covid-19 crisis. BMJ. 2020;369:m1435. https://doi.org/10.1136/bmi.ml435

54. Javid B, Weekes MP, Matheson NJ. Covid-19: should the public wear face masks? BMJ. 2020;369:m1442. https://doi.org/10.1136/bmj.m1442 